\title{
Meiotic epigenetic factor PRDM9 impacts sperm quality of hybrid mice
}

\author{
Fitore Kusari ${ }^{1}$, Ondrej Mihola ${ }^{1}$, John C Schimenti ${ }^{2}$ and Zdenek Trachtulec ${ }^{1}$ \\ ${ }^{1}$ Laboratory of Germ Cell Development, Division BIOCEV, Institute of Molecular Genetics of the Czech Academy of \\ Sciences, Prague 4, Czech Republic and '2Departments of Biomedical Sciences and Molecular Biology and Genetics, \\ Cornell University, College of Veterinary Medicine, Ithaca, New York, USA
}

Correspondence should be addressed to Z Trachtulec; Email: Zdenek.Trachtulec@img.cas.cz

\begin{abstract}
Reduced fertility of male mouse hybrids relative to their parents, or hybrid sterility, is governed by the hybrid sterility 1 (Hst1) locus. Rescue experiments with transgenes carrying sequences within or near Hst 1 manifested that Hst 1 contains the gene encoding meiosis-specific histone methyltransferase PRDM9. The Prdm9 gene is responsible for partial meiotic arrest, testicular atrophy, and low sperm count in $\left(\mathrm{C57} \mathrm{BL} / 6 \mathrm{~J}\right.$ x PWD) $\mathrm{F}_{1}$ mouse hybrids. Here we report that these male hybrids suffer an additional reproductive disadvantage, decreased sperm quality, which is (i) further exacerbated by the introduction of long transgenes carrying sequences from Hst1 with incomplete Prdm9 into their genome and (ii) controlled by the Prdm9 dosage. These transgenic male hybrids displayed the features of severe oligoasthenoteratozoospermia (OAT), a human infertility syndrome characterized by a low number of spermatozoa with poor motility and morphological abnormalities. Analysis of spermiogenesis in these mice revealed acrosome detachment, aberrant elongation and condensation of the nucleus. As a result, the transgenic sperm had acrosome malformations, abnormal chromatin packaging, and fragmented DNA with elevated base oxidation, revealed by using multiple methods.

Heterozygosity for one null Prdm9 allele improved meiotic progression and sperm quality of both non- and transgenic hybrids. Our results indicate that genomic analysis of OAT patients should include consideration of allelic variants in PRDM9, and our transgenic models can serve as tools to understand the diverse molecular processes that, when perturbed, can cause this disease.

Reproduction (2020) 160 53-64
\end{abstract}

\section{Introduction}

Hybrid sterility (HS) observed among male offspring of crosses between closely related animal species acts as a reproductive barrier that prevents gene flow and maintains the identity of species (Nosil \& Schluter 2011). Genetic crosses using model organisms have identified several mechanisms underlying HS, including genic (e.g., speciation genes) (Mihola et al. 2009) and chromosomal (e.g., chromosome rearrangements) factors (Rieseberg 2001). The Dobzhansky-Muller model implies that HS is a result of incompatible interactions between divergent alleles at two or more loci (Dobzhansky 1936, Muller 1942). Thus, fertility studies in hybrids are important as they provide insights into the molecular mechanisms of speciation and reproduction.

Partially arrested spermatogenesis often results in sperm count reduction (oligospermia), sperm motility impairment (asthenospermia), and/or sperm malformation (teratozoospermia) (Yan 2009). The combination of these three phenotypes is known as oligoasthenoteratozoospermia (OAT) (Cavallini 2006). In humans, the OAT syndrome has been reported as a major cause of male infertility (Jungwirth et al.
2012). In the mouse, many genes are associated with OAT (Matzuk \& Lamb 2008), but only three (CMAK4, NANOS1, and TDRD6) have been identified in humans (Khattri et al. 2012, Kusz-Zamelczyk et al. 2013, Sha et al. 2018). Epigenetic modifications are altered in the sperm of OAT men (Navarro-Costa et al. 2010, Santi et al. 2017), but it is unclear whether these are a direct cause or a consequence of the OAT syndrome. Thus, understanding the underlying mechanisms of OAT is of great significance for both diagnosis and treatment of this syndrome.

Strains derived from house mice (Mus musculus) provide useful models for understanding many areas of biology and medicine. Three closely related house mouse subspecies, M. m. domesticus, M. m. musculus, and M. m. castaneus, diverged from a common ancestor $\sim 0.5$ Myr ago (Geraldes et al. 2008). M. m. domesticus and M. m. musculus form a hybrid zone running across Europe (Sage et al. 1986). Males from this hybrid zone (Albrechtova et al. 2012, Turner et al. 2012) and from laboratory $\mathrm{F}_{1}$ crosses between $\mathrm{C} 57 \mathrm{BL} / 6$ J (henceforth B6, domesticus) and PWD (musculus) display reduced fertility (Mihola et al. 2009, White et al. 2011). The causative factor of this $F_{1}$ hybrid sterility is PR-domain 9 
(PRDM9), the first mammalian speciation factor identified (Mihola et al. 2009). PRDM9 specifies the genomic locations of recombination hotspots in mice and humans (Baudat et al. 2010, Parvanov et al. 2010, Gregorova et al. 2018). During meiosis, PRMD9 binds DNA via its zinc finger (ZF) domain and adds trimethylation marks including H3K4me3 and H3K36me3 to the nearest nucleosome via its PR methyltransferase domain (Baudat et al. 2010, Diagouraga et al. 2018). These actions serve to recruit DNA double-strand break (DSB) machinery to mediate DSB formation (Baudat et al. 2010) that initiates meiotic recombination. Comparisons between and within species (Mihola et al. 2009, Oliver et al. 2009) show that the ZF domain of PRDM9 is highly polymorphic. The quick evolutionary turnover of the PRDM9 ZFs and their binding sites leads to asymmetric PRDM9 binding and DSBs on diverged homologous chromosomes, which can be difficult to repair and thus cause fertility problems in the inter(sub)specific hybrids (Davies et al. 2016).

To ascertain the genetic basis of mouse HS, several bacterial artificial chromosome (BAC) transgenic mouse lines have been developed covering the male-specific hybrid sterility 1 (Hst 1 ) locus on chromosome 17 encompassing several genes (Mihola et al. 2009). Two BACs expressing Prdm9 rescue the meiotic progression and fertility of azoospermic (PWD x B6) $\mathrm{F}_{1}$ and oligospermic (B6 x PWD)F $F_{1}$ male hybrids (Mihola et al. 2009, Flachs et al. 2012). In contrast, the BAC21 transgene carrying Fam 120b, Psmb1, Tpb, Pdcd2, and only truncated Prdm9 does not rescue $(P W D \times B 6) F_{1}$ hybrid sterility, and further decreases the subfertility of $(\mathrm{B} 6 \times \mathrm{PWD}) \mathrm{F}_{1}$ hybrids due to malespecific defects in both meiosis and spermiogenesis. The introduction of BAC21 in the hybrids causes a decrease in meiotic crossover rate (but not impaired meiotic DNA repair), an increase in the number of metaphase I spermatocytes displaying univalent chromosomes, and a more frequent apoptotic cell death of the secondary spermatocytes and spermatids (Mihola et al. 2020). Because the lowered sperm quantity caused by partial arrest of the testis development is sometimes accompanied by decreased sperm quality, which is reminiscent of OAT, we aimed to investigate sperm of $\left(\mathrm{B} 6 \times \mathrm{PWD}^{\mathrm{P}} \mathrm{F}_{1}\right.$ males with and without the BAC21 transgene and found the phenotypes observed in OAT. As reducing the Prdm9 dosage to one gene copy rescues the sperm quantity of (B6 x PWD)F $F_{1}$ hybrids (Flachs et al. 2012), we analyzed the sperm quality of non- and transgenic hybrids with one Prdm9 copy and uncovered improved sperm phenotypes. We conclude that the meiotic protein PRDM9 is important for normal sperm structure and motility.

\section{Materials and methods}

\section{Ethics statement}

The laboratory animal care and experiments observed The Czech Republic Act for Experimental Work with Animals (Decree No.
207/2004 Sb) as well as the Acts Nos. 246/92 Sb and 77/2004 Sb based on The European Union Directive 2010/63/EU. These experiments complied with the ARRIVE guidelines (Flachs et al. 2014) and were approved by permits Nos. 9/2016 and 16/2019 issued by the Ethics Committee for the Work with Animals of the Institute of Molecular Genetics in Prague.

\section{Mice}

The C57BL/6J strain (B6) was from The Jackson Laboratory (stock 000664). The PWD/Ph strain (PWD) was derived from wild Mus musculus musculus in Prague (Gregorova \& Forejt 2000). Transgenic mice prepared using random integration of bacterial artificial chromosome (BAC) clones CHORI-34289M8 (BAC21) and RP24-346I22 (BAC346) were previously described (Howell et al. 2005, Mihola et al. 2009, Mihola \& Trachtulec 2017). These transgenic strains were maintained on the B6 background. Both transgenes are over $100 \mathrm{~kb}$ in length and carry the mouse Psmb1, Tbp, and Pdcd2 genes; BAC21 carries only the last (ZF-coding) exon of Prdm9 and the Prdm9 transcript encompassed by BAC346 lacks the PR/SETand ZF-encoding domains. The BAC21 insertion site resides on chromosome 13 and segregates independently of the BAC346 insertion site (Mihola et al. 2020). The copy number of BAC21 is two (Mihola et al. 2009) and it is similar in BAC346 transgenic mice based on the testicular expression data (Mihola et al. 2020). The mouse Prdm9 $9^{\text {tm } 1 Y \text { mat }}$ allele on PWD background has also been published (Mihola et al. 2019).

\section{Sperm, spermatid, and spermatocyte phenotyping}

See Supplementary methods (see section on supplementary materials given at the end of this article); the statistical significance of the data was evaluated by the generalized linear model. Each point in all figures represents an individual mouse.

\section{Results \\ Poor motility (asthenospermia) of BAC21 transgenic hybrid (Tg+) mice}

Among multicopy BAC transgenes developed to dissect the genetic basis of HS, only BACs carrying sequences with complete Prdm9 rescue mouse HS (Mihola et al. 2009). In contrast, BACs with the same multiple gene content but truncated Prdm9 induce partial arrest of spermatogenesis and thus lower sperm quantity of subfertile mouse hybrids (Mihola et al. 2020). As these phenotypes are often present along with reduced sperm quality, we investigated sperm of the transgenic and control hybrids. We obtained transgenic and nontransgenic $(\mathrm{B} 6 \times \mathrm{PWD}) \mathrm{F}_{1}$ mouse hybrids by crossing B6 females heterozygous for BAC21 with PWD males. As expected (Mihola et al. 2020), (B6 x PWD)F $F_{1}$ males heterozygous for BAC21 (henceforth denoted $\mathrm{Tg}+$ ) had significantly lower epididymal sperm counts compared to nontransgenic $\left(\mathrm{B} 6 \times \mathrm{PWD}^{\mathrm{F}} \mathrm{F}_{1}(\mathrm{Tg}-)\right.$ and parental controls (B6 and PWD, Tgp) (Fig. 1A); Tg- males carried 
less sperm than Tgp (Mihola et al. 2009). The semen of $\mathrm{Tg}+$ mice also contained some round cells. Because the $\mathrm{Tg}+$ mice were still able to produce some spermatozoa, we studied their motility using computer-assisted sperm analysis (CASA). The Tg+ sperm had $\sim 80 \%$ reduction in both total and progressive motility when compared with the Tg- sperm $\left(P_{1}<0.001, P_{2}=0.039\right.$, Table 1$)$. Thus, in addition to the decreased count, the motility of sperm was also severely compromised by the presence of the BAC21 transgene.

\section{Sperm malformations (teratozoospermia) in Tg+ mice}

Normal sperm morphology is essential for fertility. To determine whether the asthenospermic $\mathrm{Tg}+$ sperm also display morphological defects, we inspected the sperm using light, fluorescence, and electron microscopy. When observed by light microscopy, most $\mathrm{Tg}$ - sperm displayed a normal, hook-shaped head and a long tail with a clearly visible midpiece, principal piece and end piece (Fig. 1B), but the majority of Tg+ sperm had severe head and tail defects (Fig. 1B). The $\mathrm{Tg}+$ mice exhibited a $70 \%$ increase in sperm head malformations compared to the $\mathrm{Tg}-$ mice $(P<0.001$, Fig. $1 \mathrm{~B}$ and $\mathrm{C}$ ). Three types of head deformities were distinguishable in Tg+ sperm: bent head and/or a tail coiled around the head (type 1), amorphous head (type 2 ), and head with reduced hooks (type 3) (Fig. 1B). Tails defects of $\mathrm{Tg}+$ spermatozoa manifested as folded tails (arrowhead, Fig. 1B) or bent tails (arrow, Fig. 1B,
A

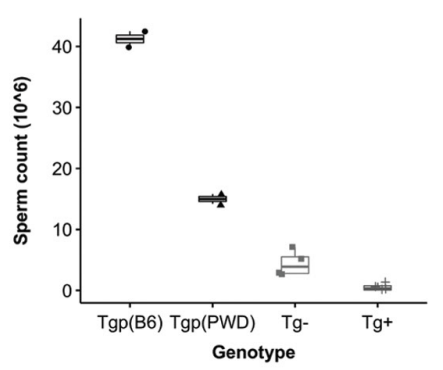

C



E



B

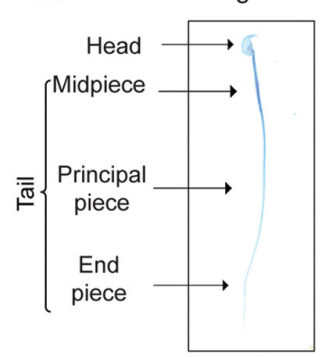

D

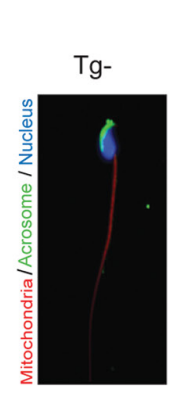



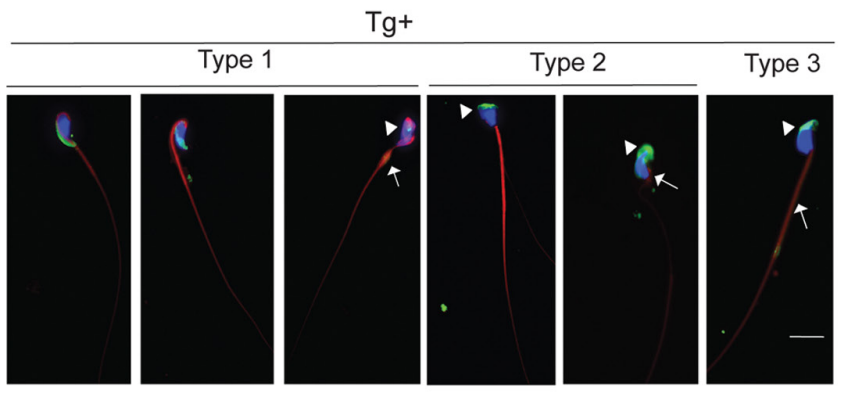

$\mathrm{F}$

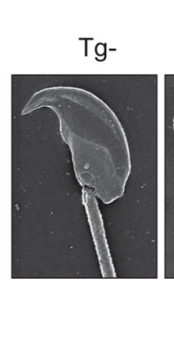

$\mathrm{Tg}+$

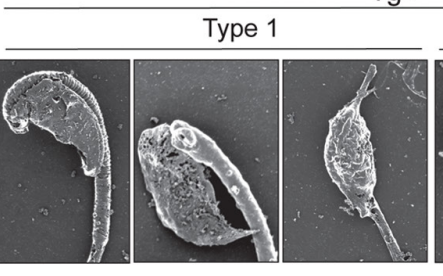

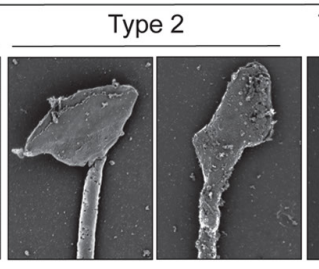
Type 3

Figure $1 \mathrm{Tg}+$ mice are oligospermic and teratospermic. (A) Boxplots of total epididymal sperm count. Each dot represents an individual mouse in all figures. (B) Representative images of Coomassie-stained sperm from Tg- and Tg+ mice. Most Tg- sperm displayed a normal head and tail, whereas $\mathrm{Tg}+$ sperm had a bent head with a tail coiled around the head (type 1), amorphous head (type 2), and reduced hook (type 3); tail abnormalities are indicated by an arrowhead and an arrow. Scale bar: $10 \mu \mathrm{m}$. (C) Boxplots of the percentage of sperm showing head and tail malformations in Tgp, Tg-, and Tg+ mice. (D) Triple staining of spermatozoa with PSA (green), DAPI (blue), and MitoTracker (red) to detect acrosome, nucleus, and midpiece mitochondria in the sperm, respectively. Scale bar: $10 \mu \mathrm{m}$. (E) Boxplots of the percentage of sperm showing acrosome and midpiece malformations. Two B6 and one PWD males were included as Tgp controls in (A), (C), (E), and the experiments described below using three Tgp mice. (F) Scanning electron micrographs of normal (Tg-) and abnormal Tg+ sperm heads. Scale bar: $5 \mu$ m. Micrographs of sperm tails are shown in Supplementary Fig. 1. 
Table 1 CASA results manifest asthenospermia in transgenic hybrid mice.

\begin{tabular}{llcc}
\hline Genotype & $\boldsymbol{n}$ & Motility $(\%)$ & Progressive motility $(\%)$ \\
\hline Tg+ & 3 & $5.7 \pm 0.6$ & $1.3 \pm 0.6$ \\
Tg- & 3 & $37.3 \pm 4.0$ & $7.7 \pm 0.6$ \\
Tgp & 4 & $67.3 \pm 2.9$ & $25.5 \pm 4.7$ \\
\hline
\end{tabular}

Values are expressed as mean \pm s.D.; $n$, number of males. Tgp controls included two PWD and two B6 males.

$p=0.007)$. A lower percentage of $\mathrm{Tg}-$ spermatozoa displayed head and tail malformations, and these defects were significantly underrepresented in the Tgp sperm (Fig. 1C). We performed triple-color staining of sperm structures using pea agglutinin (PSA), which recognizes the sperm acrosome, DAPI for nucleus labeling, and MitoTracker for active mitochondria in the midpiece (Fig. 1D). The acrosomes of the Tgspermatozoa acquired the typical crescent moonshape, whereas the $\mathrm{Tg}+$ spermatozoa exhibited various defects in the acrosome shape, size, and position (arrowheads, type 1 to 3, Fig. 1D). The acrosome malformations were increased by $\sim 68 \%$ in $\mathrm{Tg}+$ compared to the Tg- spermatozoa $(P=0.001$, Fig. 1E). The mitochondria located in the midpiece region, responsible for sperm motility, also showed various defects in the Tg+ sperm (Fig. 1D). Mitochondria were wrapped around the nucleus and contained a bulge (arrow, type 1, Fig. 1D), in some cases aggregated near the nucleus (arrow, type 2, Fig. 1D), or were weakly stained with MitoTracker (arrow, type 3, Fig. 1D). These midpiece defects were elevated by $\sim 74 \%$ compared with those of theTg- mice $(P<0.001$, Fig. 1E). Examination by scanning electron microscopy (SEM) (Fig. 1F) supported these findings and revealed that in one of the common deformities of Tg+ sperm, where the head was bent toward the tip of the tail (type 1), the head and the tail seemed to be connected by tissues resembling residual cytoplasm, which is normally removed during spermiogenesis (Fig. 1F).

\section{Ultrastructure abnormalities in Tg+ sperm and spermatids}

To investigate whether the poor motility of Tg+ sperm is caused by defects in the flagellum organization, we examined sperm by transmission electron microscopy (TEM) (Fig. 2 and Supplementary Fig. 2). Sections across the midpieces of Tg+ flagella showed disorganized mitochondria and irregular arrangements both of the nine outer dense fibers (ODFs) and the microtubular axoneme in the center (Fig. 2E). Both ODFs and the microtubules of the axoneme appeared to be irregular in number in the principal piece (Fig. 2F). In contrast, these flagellar components were intact in most Tgsperm (Fig. 2B and C). The abnormal organization of these sperm tail components in Tg+ compared to Tg$\left(P_{1}=0.039, P_{2}=0.051\right)$ suggests a failure of $\mathrm{Tg}+$ sperm tail development during spermiogenesis and likely accountsfor the observedasthenospermia. Additionally, TEM confirmed that the nucleus and acrosome of $\mathrm{Tg}+$ sperm were abnormally shaped (Fig. 2D) and acrosomes were detached. The nuclei showed regions of reduced electron density (arrow, Fig. 2D) in $\mathrm{Tg}+$ compared to $\mathrm{Tg}-$ (Fig. 2D versus $2 \mathrm{~A}$ ), suggesting defective chromatin condensation. To test whether sperm defects present in the Tg+ epididymal sperm originated in the spermatids, we compared all four phases of spermiogenesis between the genotypes using peanut agglutinin (PNA) staining of testicular sections detected by fluorescence microscopy (Fig. 3A). We observed single acrosomes in round spermatids (Fig. 3A), which then grew into cap-like structures (Fig. 3A) without obvious differences in the shape between $\mathrm{Tg}-$ and $\mathrm{Tg}+$ mice (Fig. 3B). By the third (acrosome) phase, the acrosomal structure of $\mathrm{Tg}+$ spermatids failed to acquire the conical shape seen in $\mathrm{Tg}-$ spermatids $(P=0.044)$ (Fig. $3 \mathrm{~A}$ and $\mathrm{C}$ ). Consequently, the acrosomes of $\mathrm{Tg}+$ elongated spermatids were deformed at the last (maturation) phase compared to $\mathrm{Tg}-(P=0.005)$, which displayed


Figure 2 Sperm ultrastructure changed in $\mathrm{Tg}+$ mice. (A) Normal nuclear and acrosomal morphology prevailing in Tg- sperm. Scale bar: $2 \mu \mathrm{m}$. (B) Mitochondria encircled the nine ODFs and axonemal microtubules in the midpiece. Scale bar: $0.5 \mu \mathrm{m}$. (C) FS, ODFs and Mt appeared to be normally arranged in the principal piece. Scale bar: $1 \mu \mathrm{m}$. (D) Abnormal morphology of the nucleus and acrosome. Scale bar: $1 \mu \mathrm{m}$. (E) Midpiece and (F) principal piece also displayed abnormal ultrastructure; scale bars: 0.5 and $0.2 \mu \mathrm{m}$. Nu, Nucleus; Ac, Acrosome; M, Mitochondria; Mt, Microtubules; FS, Fibrous Sheath. 

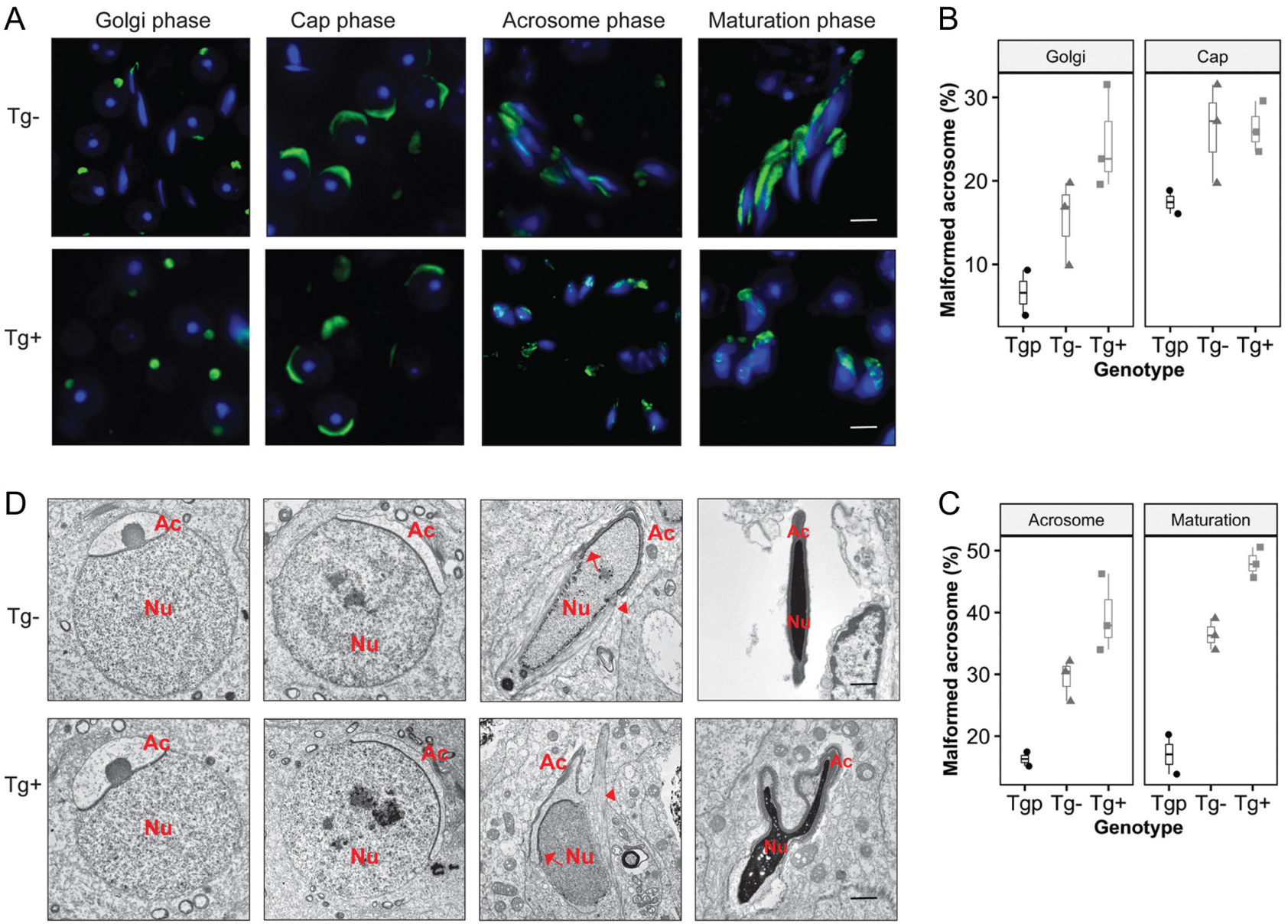

Figure 3 Abnormal morphology of Tg+ spermatids. (A) Testis sections of spermatids stained with acrosomal marker PNA (green) and DAPI (blue), and analyzed by fluorescence microscopy. Scale bars: $10 \mu \mathrm{m}$. (B) Boxplots of the percentage of spermatids with abnormal acrosomes at Golgi and cap phases, and (C) at acrosome and maturation phases. PWD males served as Tgp control. (D) TEM micrographs of Tg- and Tg+ spermatids. Tg+ mice displayed defects of spermatid structures at the late (acrosome and maturation) stages of spermiogenesis. Approximately $41 \%$ of elongated spermatids showed abnormal chromatin condensation in $\mathrm{Tg}+$ males compared to $21 \%$ in $\mathrm{Tg}-(\sim 50$ elongated spermatids counted per mice, one mouse per genotype). Scale bars: $2 \mu \mathrm{m}$. Arrows and arrowheads indicate the acroplaxome and the manchette, respectively. Ac, Acrosome; Nu, Nucleus.

the typical elongated, moon-shape structure (Fig. 3A and C). Differences in the acrosome shape between Tg- and Tgp spermatids were also noted at the acrosome $(P=0.025)$ and maturation $(P<0.001)$ phase (Fig. 3C). These results were confirmed by TEM analysis (Fig. 3D); Tg+ mice displayed detached acrosomes from nuclei, abnormal spermatid elongation and nuclear condensation during the last two phases of spermiogenesis (Fig. 3D). The acroplaxome and the manchette, cytoskeletal structures essential for acrosome attachment and sperm head shaping (Kierszenbaum \& Tres 2004), were scattered in Tg+ spermatids (Fig. 3D). These data indicate that the presence of the BAC21 transgene impaired late stages of spermiogenesis resulting in morphological and ultrastructural sperm defects in the mouse hybrids.

\section{Abnormal chromatin packaging observed in Tg+ mice}

To verify the TEM data that suggested compromised chromatin condensation in the Tg+ sperm, we used Chromomycin A3 (CMA3) staining (Bianchi et al. 1996). We found that $\mathrm{Tg}+$ mice had a $45 \%$ higher occurrence of sperm heads with CMA3-positive staining compared to the Tg- mice ( $P=0.005$, Fig. $4 \mathrm{~A}$ and $\mathrm{B}$ ). To confirm this result, we used another parallel approach to analyze sperm chromatin condensation, flow cytometry after staining with propidium iodide (PI-FACS), a DNA intercalating agent (Vicari et al. 2002). The entry of PI into the nuclear DNA of some Tg+ sperm was higher compared to that of the $\mathrm{Tg}-$ and parental mouse sperm $(P=0.009$, Fig. $4 \mathrm{C})$. Consistent with TEM results, both the CMA3 and PI-FACS analyses displayed defective chromatin condensation in sperm produced by $\mathrm{Tg}+$ mice. 

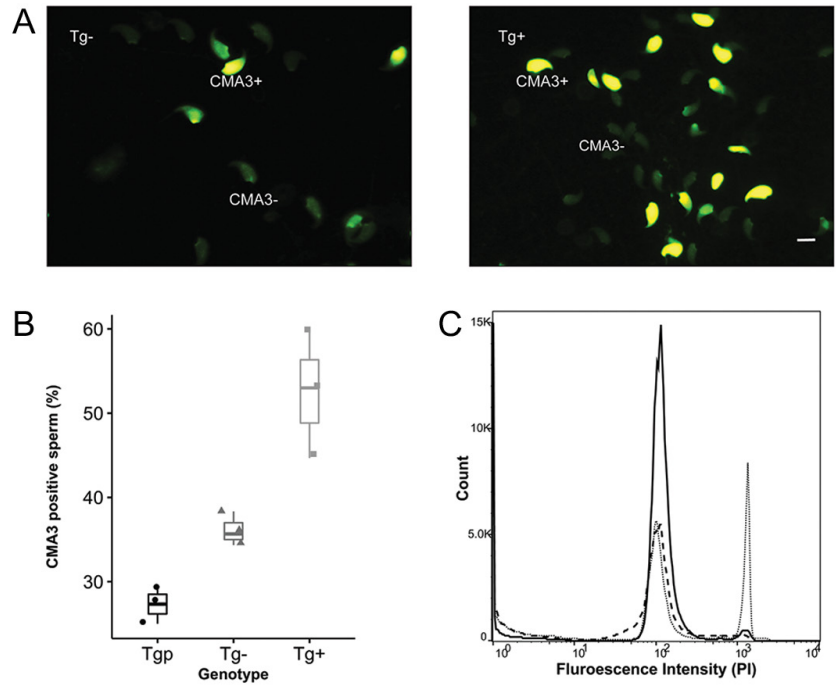

Figure 4 Altered chromatin condensation in Tg+ mouse sperm. (A) Chromomycin A3 (CMA3) staining in Tg- and Tg+ mice. Sperm with yellow/green fluorescence are positive for CMA3 staining (CMA3+) and indicate reduced chromatin condensation, whereas sperm with weak to no fluorescence (CMA3-) display normal chromatin condensation. Scale bar: $10 \mu \mathrm{m}$. (B) Boxplots of the percentage of CMA3+ sperm in Tgp, Tg-, and Tg+ mice (means of 300 cells per animal, in triplicates). (C) Flow cytometry analysis of sperm stained with propidium iodide (PI). Some sperm from $\mathrm{Tg}+$ mice were stained more strongly with PI (indicated by a higher fluorescence peak in the histogram, dashed line) than Tg- and Tgp sperm (dotted and solid lines).

\section{Increased DNA damage and DNA oxidation in Tg+ sperm}

The abnormal chromatin packaging observed in $\mathrm{Tg}+$ mice could influence the genome integrity. To test this hypothesis, we investigated the sperm DNA damage and oxidation using three approaches. To evaluate the integrity of the sperm DNA, we first utilized the alkaline comet assay (single-cell gel electrophoresis of denatured DNA). The denatured, fragmented DNA migrates farther under the influence of an electric field (generating a comet tail) than intact DNA, which remains within the confines of the nucleus (Singh et al. 1988, Kusari et al. 2017). The average level of sperm DNA damage expressed as the percentage of DNA in the comet tail was higher for the $\mathrm{Tg}+$ versus $\mathrm{Tg}-$ mice $(P<0.001$, Fig. $5 \mathrm{~A}$ and $\mathrm{B})$ and for parental controls (Fig. 5A). Second, we estimated the amount of oxidized bases in the sperm DNA using enzyme formamidopyrimidine-DNA glycosylase (Fpg). This enzyme recognizes oxidized pyrimidines and purines, removes these oxidized bases, and nicks DNA in the sites of the lesions. The resulting DNA nicks increase the comet tail measurable by the alkaline comet assay. The addition of the Fpg enzyme caused a $~ 38 \%$ increase in the percentage of DNA in the comet tail of $\mathrm{Tg}+\mathrm{sperm}$ compared to an $\sim 7 \%$ increase in $\mathrm{Tg}-$ sperm $(P<0.001)$. Third, we detected a common oxidative DNA lesion,
A



B



C

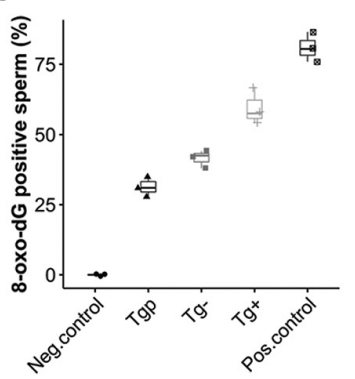

D
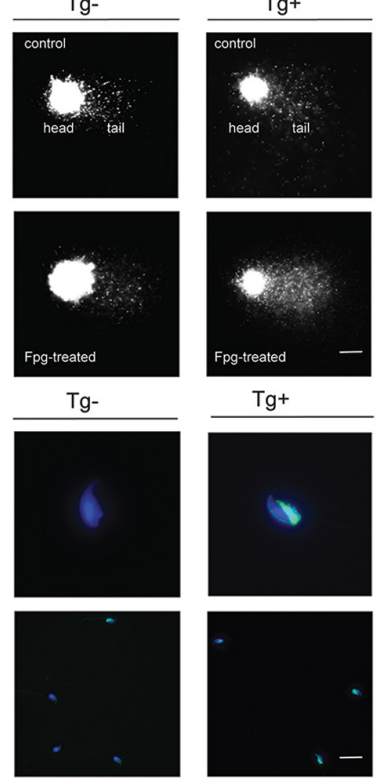

$\mathrm{Tg}+$

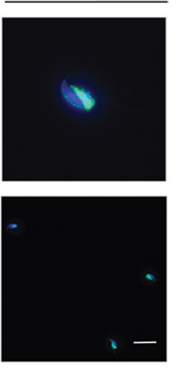

Figure 5 Increased DNA damage and oxidation in Tg+ sperm. (A) Boxplots of the percentage of DNA in the comet tail (medians from 50 cells per male) in the control and Fpg-treated sperm. (B) Representative images of the alkaline comet assay in Tg- and Tg+ sperm. This assay revealed an increased number of DNA breaks in Tg+ sperm (note a larger comet tail) compared to Tg- sperm. Treatment with formamidopyrimidine-DNA glycosylase (Fpg) led to an increased DNA content in the comet tail compared to the control (Fpg-untreated) sperm in Tg+. Scale bar: $20 \mu \mathrm{m}$. (C) Boxplots of the percentage of 8-oxo-dG positive sperm (of 200 sperm per male) in Tgp, Tg-, and Tg+ mice plus controls (no antibody and treatment with $\mathrm{H}_{2} \mathrm{O}_{2}$ ). (D) Immunostaining of sperm with antibody against 8-oxo-dG. Scale bar: $10 \mu \mathrm{m}$.

8-hydroxy-2'-deoxyguanosine (henceforth 8-oxo-dG), in the sperm nuclei using immunostaining and found that the level of sperm positive for 8 -oxo-dG was $\sim 43 \%$ higher $(P=0.004)$ compared to the $\mathrm{Tg}-$ mice. The parental control sperm was similar to other WT sperm (Chabory et al. 2009) in displaying $~ 31 \%$ cells positive for 8-oxo-dG, which was significantly less compared to the Tg- sperm ( $P=0.043$, Fig. 5C). Together, these three observations indicated that the transgene presence compromised the sperm DNA integrity and increased the amount of oxidized DNA base lesions.

\section{Reduced sperm quality of nontransgenic (B6 $x$ PWD) $F_{1}$ males}

The nontransgenic $(\mathrm{B} 6 \quad \mathrm{x} \quad \mathrm{PWD}) \mathrm{F}_{1}$ intersubspecific hybrids ( $\mathrm{Tg}-$ ) differ from the parental strains by a lower sperm count, testicular weight (Mihola et al. 2009), and reduced chromosomal synapsis during pachynema (Flachs et al. 2012). We investigated other sperm phenotypes of $\mathrm{Tg}-$ males and compared them to those of their parental controls. The Tg- sperm displayed decreased motility (Table 1) and increased 
malformations of the sperm head and tail $\left(P_{1}=0.013\right.$, $P_{2}=0.026$, Fig. 1C). Malformations of the acrosome in elongating spermatids (Fig. 3C) and subsequent defects of both acrosome and midpiece in mature sperm $\left(P_{1}=0.043, P_{2}=0.019\right.$, Fig. $\left.1 \mathrm{E}\right)$, indicated that the sperm defects of the Tg- mice originated from impaired spermiogenesis. While the TEM (Supplementary Fig. 2) and CMA3 analyses suggested a trend of reduced chromatin condensation compared to parental controls, the results did not reach statistical significance $(P=0.062$, Fig. 4B). Although the alkaline comet assay with/out Fpg treatment did not reveal elevated sperm DNA oxidation $(P=0.312$, Fig. $5 \mathrm{~A})$, the 8-oxo-dGimmunostaining (Fig. 5C) showed increased oxidation in Tg- compared to Tgp sperm $(P=0.043)$. Thus, the nontransgenic hybrids manifested a decreased sperm quality in comparison to parental mice.

\section{Another transgenic hybrid, BAC346, phenocopies the sperm of the BAC21 hybrid}

To confirm the transgene-induced OAT causality in $\mathrm{Tg}+$ mouse hybrids and to translate such a phenotype into mechanistic insights, we investigated whether these sperm phenotypes emerge by insertional mutagenesis. To assess this hypothesis, we used mice carrying another long transgene prepared by random genomic integration (BAC346, see Methods). This transgene carries a gene content highly similar to BAC21 (Mihola \& Trachtulec 2017), including a truncated Prdm9 lacking the PR/SET domain essential for its function. The epididymal sperm count of the BAC346 transgenic hybrid was significantly lower than that of $\mathrm{Tg}-(P=0.002$, Fig. $6 \mathrm{~A})$, and there were more spermatozoa with acrosome and midpiece abnormalities compared to the BAC346 nontransgenic controls $\left(P_{1}<0.001, P_{2}=0.006\right.$, Fig. 6B). The alkaline comet assay with and without Fpg revealed elevated DNA damage $(P=0.006)$ and DNA oxidation $(P<0.001)$ in spermatozoa of these mice relative to nontransgenics (Fig. 6C). These analyses indicate similar sperm phenotypes of BAC346 and BAC21 transgenic hybrids, suggesting an effect independent of the insertion sites.

\section{Reducing Prdm9 gene dosage partially rescues normal sperm quality of $\mathbf{T g}+$ mice}

The Prdm9 gene contributes to genetic incompatibilities in mouse hybrids resulting in fertility reduction (Mihola et al. 2009). Manipulation of the Prdm9 gene copy number rescues the testicular weight and sperm quantity of $\mathrm{Tg}$ - hybrids (Flachs et al. 2012); we thus asked whether the Prdm9 gene also acts on the sperm quality of $\mathrm{Tg}+$ and $\mathrm{Tg}-$ hybrids by investigating the effect of decreasing the Prdm9 gene dosage to one copy. We generated Tg+ mouse hybrids with two and one Prdm9 copies by crossing heterozygous transgenic B6 females to PWD males heterozygous for the Prdm9 knockout

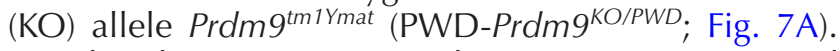
Based on this mating strategy, the $F_{1}$ generation consisted of four types of (B6 $\times$ PWD) $F_{1}$ mouse hybrids (Fig. 7A), transgenic and nontransgenic with one or two gene copies of Prdm9: $\mathrm{Tg}^{+/-} \operatorname{Prdm} 9^{B 6 / K O}$ (hereafter referred to as $\left.\mathrm{Tg}+\operatorname{Prdm} 9^{\mathrm{KO}}\right), \mathrm{Tg}^{-/-} \operatorname{Prdm} 9^{\mathrm{B} 6 / \mathrm{KO}}$ (Tg-Prdm9 ${ }^{\mathrm{KO}}$ ), $\mathrm{Tg}^{+/-} \operatorname{Prdm} 9^{B 6 / P W D}(\mathrm{Tg}+)$ and $\mathrm{Tg}^{-/-} \operatorname{Prdm} 9^{B 6 / P W D}(\mathrm{Tg}-)$. Sperm counts of $\mathrm{Tg}+\operatorname{Prdm} 9^{\mathrm{KO}}$ males were higher in comparison with $\mathrm{Tg}+$ and $\mathrm{Tg}-$ males $\left(P_{1}<0.001\right.$, $P_{2}=0.03$, respectively, Fig. $\left.7 \mathrm{~B}\right)$. The $\mathrm{Tg}+\operatorname{Prdm} 9^{\mathrm{KO}}$ mice had a significantly elevated percentage of motile and progressive sperm compared with $\mathrm{Tg}+\left(P_{1}<0.001\right.$, $\left.P_{2}<0.001\right)$ and Tg- mice $\left(P_{1}=0.002, P_{2}=0.013\right.$, Fig. 7C). The morphological analyses of sperm revealed restoration of the head and tail sperm defects in the $\mathrm{Tg}+\operatorname{Prdm} 9^{\mathrm{KO}}$ mice compared to Tg+ $\left(P_{1}<0.001, P_{2}<0.001\right.$, Fig. 7D) and $\mathrm{Tg}-$ males $\left(P_{1}<0.001, P_{2}=0.044\right)$. As expected from these parameters, the transgenic hybrid males with only one copy of Prdm9 produced offspring (7.1 \pm 1.1 per female per month). The decrease in the Prdm9 gene dosage normalized the sperm count of $\mathrm{Tg}+$, so that $\mathrm{Tg}+\operatorname{Prdm} 9^{\mathrm{KO}}$ was comparable to Tg-Prdm $9^{\mathrm{KO}}(P=0.762$, Fig. $7 \mathrm{~B})$ and to the PWD parental control $(P=0.987)$. However, sperm motility and morphology were different between $\mathrm{Tg}+\operatorname{Prdm} 9^{\mathrm{KO}}$ versus $\mathrm{Tg}-\mathrm{Prdm} 9^{\mathrm{KO}}\left(P_{1}=0.054\right.$, $\left.P_{2}=0.006\right)$ and versus Tgp $\left(P_{1}=0.014, P_{2}=0.023\right.$; Fig. $7 C$ and D), suggesting that these sperm phenotypes were affected by the transgene presence. No significant differences were observed in the sperm count, motility and morphology between $\mathrm{Tg}-\operatorname{Prdm} 9^{\mathrm{KO}}$ and parental controls (Fig. 7B, C and D).
A

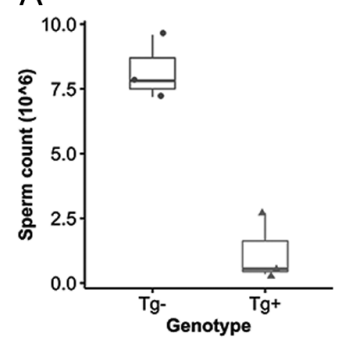

https://rep.bioscientifica.com
B

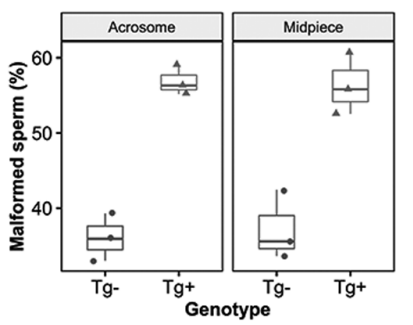

C

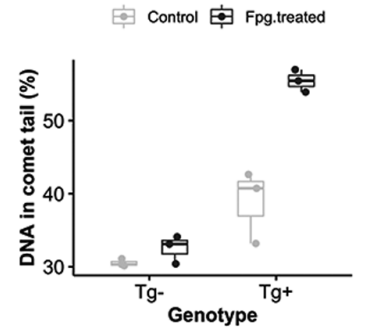

Figure 6 The effect of transgenes on hybrid sperm is not limited to BAC21. BAC346 transgenic (B6 $\times$ PWD) $\mathrm{F}_{1}$ hybrids ( $\mathrm{Tg}+$ ) display (A) Decreased sperm count, (B) increased percentage of sperm with acrosome and midpiece malformations compared to the Tg- controls. (C) The alkaline comet assay uncovered more DNA breaks (light grey) and the comet assay with Fpg showed more DNA oxidation (black) in BAC346 Tg+ versus $\mathrm{Tg}$ - sperm. 

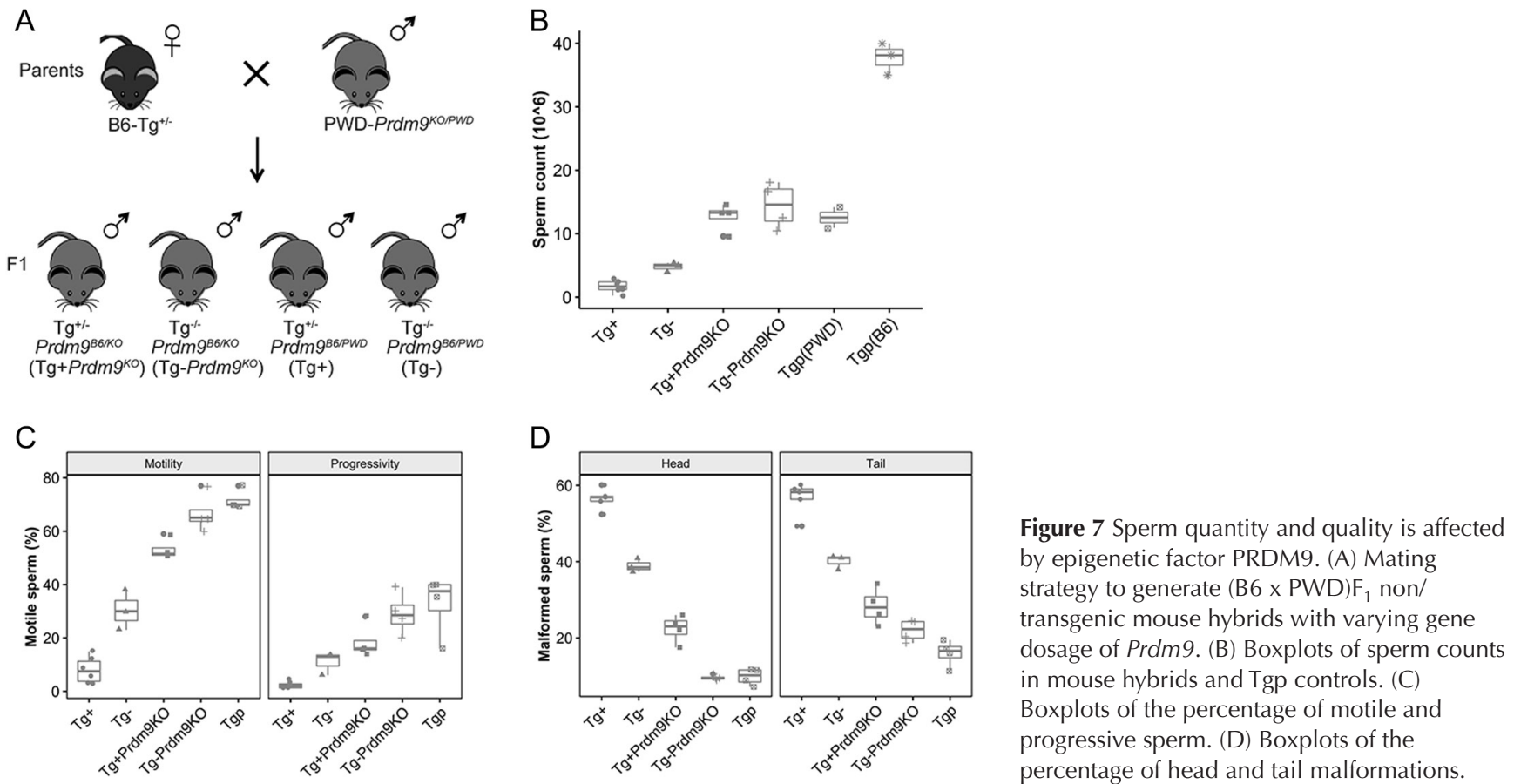

Since the decreased Prdm9 dosage in (B6 x PWD) $\mathrm{F}_{1}$ hybrids improves meiotic progression by promoting efficient synapsis and sex body (SB) formation (Flachs et al. 2012), we tested whether this mechanism can also explain the higher sperm count and quality in $\mathrm{Tg}+\operatorname{Prdm} 9^{\mathrm{KO}}$. We analyzed nuclear spreads of $\mathrm{Tg}+\operatorname{Prdm} 9^{\mathrm{KO}}$ and $\mathrm{Tg}+$ testes immunostained for markers of chromosomal synapsis (SYCP3, SYCP1) and SB formation (yH2AX) (Fig. 8A). Homologous autosomes were fully synapsed and $\mathrm{SB}$ formed (encompassing just sex chromosomes) in $~ 58 \%$ of pachytene nuclei from $\mathrm{Tg}+\operatorname{Prdm} 9^{\mathrm{KO}}$ compared to only $\sim 45 \%$ in $\mathrm{Tg}+$ males $(P=0.032)$.

Meiosis progression requires proper establishment of the pericentric heterochromatin $(\mathrm{PCH})$ structure (Takada et al. 2011), as its defects lead to asynapsis of mouse chromosomes (Takada et al. 2011), and the loss of $\mathrm{PCH}$ histone modification marks (e.g., H3K9me3) disrupts heterochromatin and genome stability (Peng \& Karpen 2009). These meiotic defects are similar to those seen in $\mathrm{Tg}+$, we hypothesized that the $\mathrm{Tg}+$ mice might have defective $\mathrm{PCH}$ and tested whether PRDM9 affects this structure. We observed a similar H3K9me3 signal distribution in $\mathrm{Tg}+\mathrm{Prdm} 9^{\mathrm{KO}}$ and $\mathrm{Tg}+$ mice detectable at the DAPI-rich PCH regions in meiotic and post-meiotic cells, indicating that PRDM9 did not affect this $\mathrm{PCH}$ histone modification pattern (Fig. 8B). These results may suggest that the chromatin defects observed in elongating spermatids and mature sperm of $\mathrm{Tg}+$ mice were not the result of large-scale defects in the $\mathrm{PCH}$ structure. In conclusion, the reduced Prdm9 dosage improved sperm motility and morphology in both non- and transgenic hybrids, likely due to more successful execution of meiotic events such as synapsis and SB formation.

\section{Discussion}

Histone-3-methyltransferase PRDM9 has a welldocumented role in $\mathrm{F}_{1}$ hybrid sterility (Mihola et al. 2009) and in the initiation of meiotic recombination in mammals (Baudat et al. 2010). We show here, using a reduced Prdm9 dosage, that PRDM9 levels are important not only for meiotic progression and sperm quantity, but also for the sperm motility and morphology of (B6 x PWD) $F_{1}$ hybrids. This decreased level of PRDM9 protein probably counteracts the negative effects of Prdm9 interaction with loci that impair spermatogenesis progression of mouse hybrids, should it be the differentially eroded meiotic recombination hotspots (Davies et al. 2016) or other loci. The genomic region of 62 megabases carrying Prdm9 affects the number of round spermatids and the presence of multinuclear cells in mouse $F_{2}$ hybrids (Schwahn et al. 2018). Spermiogenesis defects (Fig. 3) were found in both $\mathrm{Tg}-$ and $\mathrm{Tg}+$ mice, but their effects on spermatozoa were completely or partially rescued by a decreased Prdm9 dosage (Fig. 7), suggesting an additional postmeiotic role of PRDM9. Because PRDM9 expression is restricted to spermatocytes during meiotic prophase I (Sun et al. 2015), it seems unlikely that it could directly influence spermatid differentiation. For instance, chromatin compaction appears to be affected in elongating spermatids undergoing nuclear condensation, a process that requires proper postmeiotic gene expression to ensure histone replacement by protamines (Dowdle et al. 2013). We speculate that the molecular interactions of PRDM9 with other chromatin remodelers (Parvanov et al. 2017) linked to 

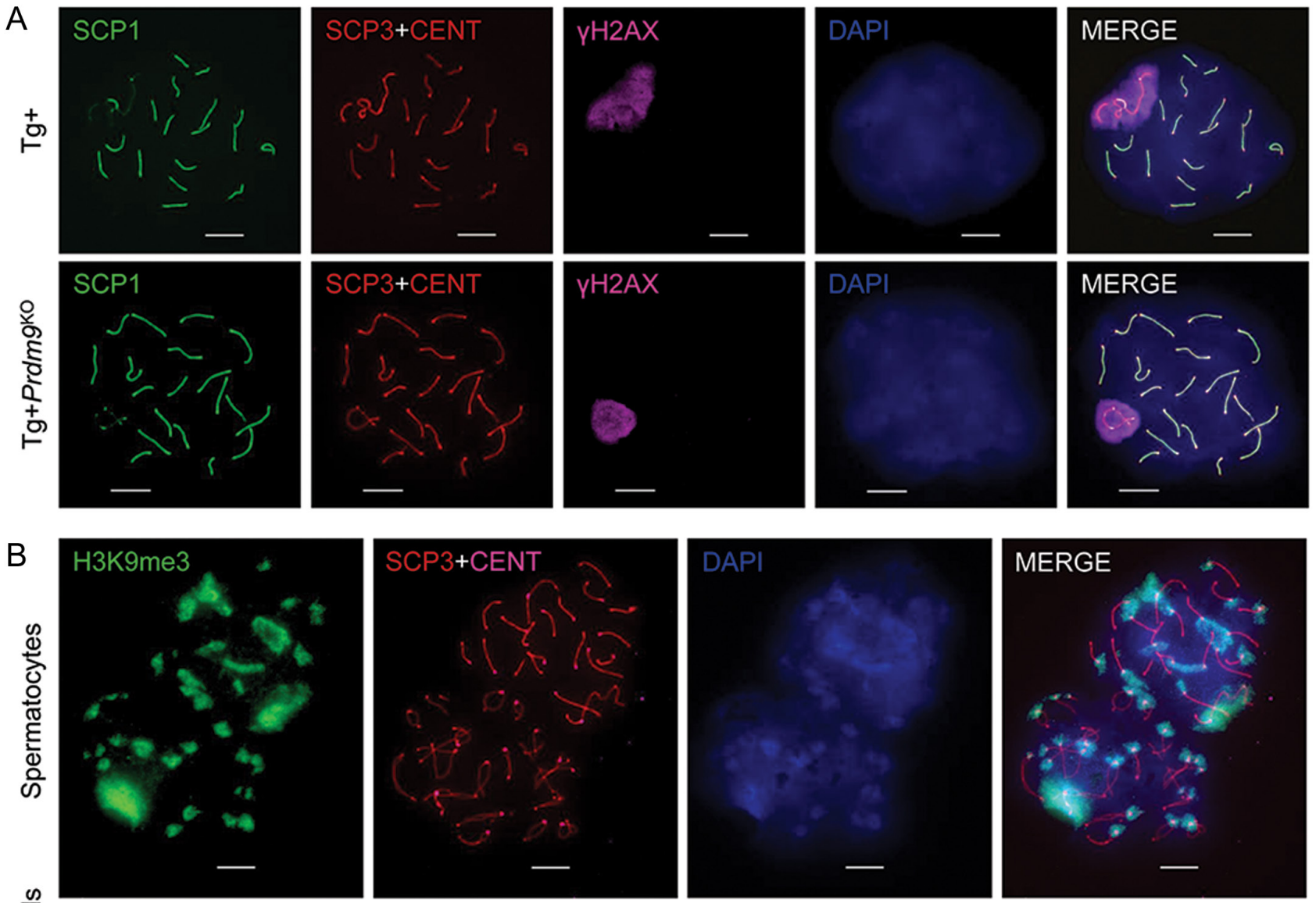

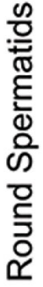

H3K9me3
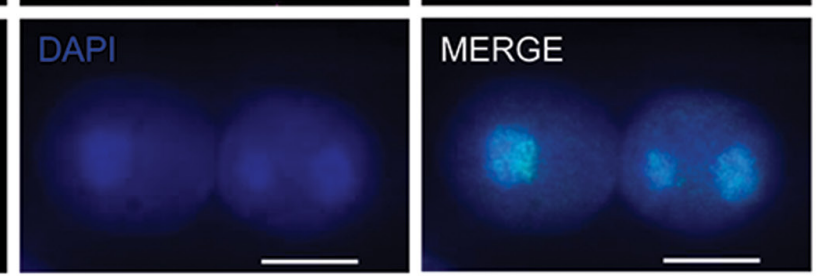

Figure 8 Chromosomal synapsis but not heterochromatin formation of Tg+ spermatogenic cells depends on Prdm9. (A) Representative images of nuclei from adult testicular spreads indirectly labeled using antibodies against synaptonemal complex proteins (SYCP1 and SYCP3), centromeres (CENT), and DSBs under repair $(\gamma \mathrm{H} 2 \mathrm{AX})$, and counterstained for DNA with DAPI. The upper images show a Tg+ pachytene nucleus (50-70 counted per each of 5 animals) with two unsynapsed autosomes encompassed in the SB. The lower images capture a completely synapsed (normal) pachytene nucleus from $\mathrm{Tg}+\operatorname{Prdm} 9^{\mathrm{KO}}$. In total, 50-70 nuclei from $\mathrm{Tg}+\operatorname{Prdm} 9^{\mathrm{KO}}$ were analyzed per animal (4 animals). Scale bars: 10 $\mu \mathrm{m}$. (B) Adult nuclear spreads stained with DAPI and immunolabeled for heterochromatin marker H3K9me3, synaptonemal complex, and centromeres. In all 20 spermatocytes and 211 round spermatids investigated from both $\mathrm{Tg}+$ and $\mathrm{Tg}+\mathrm{Prdm} \mathrm{g}^{\mathrm{KO}}$, the DAPI-rich signal co-localized with the H3K9me3 signal as in these four representative cells. Scale bars: $10 \mu \mathrm{m}$.

histone replacement (e.g., CDYL) (Liu et al. 2017) in the repaired recombination sites may influence subsequent chromatin compaction events. Alternatively, chromatin defects observed in elongated spermatids may be due to compromised spermiogenesis rather than a specific PRDM9-related effect.

Our $\mathrm{Tg}+$ mouse hybrid model recapitulates all three characteristics of the human OAT: (1) low sperm output; (2) poor motility; and (3) head and tail structural abnormalities. The OAT phenotype has been previously reported in at least eleven types of mutant mice (Supplementary Table 1). Four of these reports did not investigate the sperm chromatin condensation, three found it intact, and four detected impaired chromatin condensation (Supplementary Table 1). Only one of these eleven reports described the analysis of the DNA integrity of spermatozoa and found it intact (Liu et al. 2018). Such phenotypic variability among the mouse models and human patients suggests that different mechanisms may underlie the OAT subtypes. Thus, $\mathrm{Tg}+$ represents an animal model to study certain types of unexplained OAT cases in men, displaying sperm chromatin defects and DNA damage (Liu et al. 2004, Rahiminia et al. 2018). 
Defective chromatin condensation within the sperm nucleus, such as that observed in both mice and humans with protamine deficiency, is associated with DNA damage and fertility problems (Cho et al. 2003, Torregrosa et al. 2006). Our findings support the idea that improper chromatin condensation in sperm manifests with DNA damage and oxidation, thereby impairing sperm quality (Figs 4 and 5). We observed sperm with deformed nuclei and acrosomes, the acrosomes being frequently detached from the nuclei. The malformations of both the nucleus and the acrosome are common phenotypes in some OAT men (Reichart et al. 2000, El-Kamshoushi et al. 2013). These abnormalities of the sperm head structures appear to be common for a variety of genetic defects that perturb the structure and function of the mouse acrosomeacroplaxome-manchette complex (Kierszenbaum \& Tres 2004, Akhmanova et al. 2005, Zhou et al. 2009). In line with these studies, we noticed that this complex was impaired in $\mathrm{Tg}+$ mice during spermiogenesis, and as a result might be involved in the cascades that lead to sperm defects. The manchette also contributes to the transport of proteins necessary for the assembly of axoneme and ODFs into the growing sperm tail via a process known as intramanchette transport (Kierszenbaum 2002, Kierszenbaum et al. 2011). Abnormal mitochondria arrangement and/or axoneme structure have been reported in some human OAT patients (Baccetti et al. 2006, Mitchell et al. 2006), suggesting that a similar mechanism may underlie these malformations in mice and humans.

Because the transgenic mouse hybrids share the same genetic background with the non-transgenics, the OAT phenotype severity observed in the $\mathrm{Tg}+$ males is likely a consequence of the transgene. Although the overall effect of the transgene presence exacerbated the sperm quantity and quality, some spermatozoa displayed normal morphology and motility, consistent with some males producing a few offspring (Mihola et al. 2020). The integration sites for BAC21 and BAC346 segregate independently (Mihola et al. 2020), and insertional mutagenesis thus cannot explain the OAT phenotype.

Deletion of a Prdm9 copy rescued both sperm count and sperm quality in $\mathrm{Tg}-$ males, but the $\mathrm{Tg}+$ sperm quality was rescued only partially (Fig. 7), indicating that some sperm parameters are controlled by the transgenes via a mechanism independent of Prdm9. The phenotypic similarity of BAC346 and BAC21 transgenic hybrids and the finding that the sperm count correlates inversely with increased Psmb1 mRNA levels encompassed by both BACs (Mihola et al. 2020) support the role of common genes expressed by both transgenes in the observed sperm phenotypes of these mice. PSMB1 and other proteasomal proteins were found to be overexpressed in the sperm of OAT men (Agarwal et al.
2015), suggesting that enhanced proteasome activity may cause, accompany, or exacerbate this disorder.

Sperm head and tail malformations as well as reduced motility have been detected and genomic loci mapped in mouse hybrids, see for example, (Larson et al. 2018), but here we describe the malformations in finer detail. The refinement was possible due to the enrichment of these sperm defects in Tg+ hybrids. Our results establish a novel role for PRDM9 in regulating normal sperm quality of hybrids and provide a foundation to further elucidate its mechanism of action. While caution is vital before extrapolating from mouse to human disorders, our study urges an investigation of whether coding or regulatory variants in the PRDM9 gene are present in patients with idiopathic OAT.

\section{Supplementary materials}

This is linked to the online version of the paper at https://doi. org/10.1530/REP-19-0528.

\section{Declaration of interest}

The authors declare that there is no conflict of interest that could be perceived as prejudicing the impartiality of the research reported.

\section{Funding}

This work was supported by CSF (16-19158S, 19-06272S), by CAS (RVO 68378050), by MEYS (LQ1604, LM2015040, LM2018129), by ERDF (CZ.02.1.01/0.0/0.0/16_013/000177 5, CZ.1.05/1.1.00/02.0109, CZ.1.05/2.1.00/19.0395), OPPK (CZ.2.16/3.1.00/21547), and TACR (LO1419). F K was partly supported by a PhD scholarship from Charles University in Prague.

\section{Author contribution statement}

$\mathrm{F} \mathrm{K}$ and $\mathrm{Z} \mathrm{T}$ designed the experiments. $\mathrm{F} \mathrm{K}$ performed sperm phenotyping, testis histology, and statistics; $O M$ executed nuclear spread experiments. J C S contributed reagents. O M and J C S contributed discussion. Z T supervised the study. F K, J C S, and ZT wrote the paper.

\section{Acknowledgements}

The authors thank M Fickerová, K Křivánková, and P Valtrová for mice genotyping; Dr K Hortová (Institute of Biotechnology of the Czech Academy of Sciences (CAS), Vestec) for the Comet assay scoring software, and the animal facility of the Institute of Molecular Genetics (IMG CAS) for mouse keeping. TEM data were produced at the Microscopy Centre - Electron Microscopy Core Facility of IMG CAS in Prague and SEM data at the Imaging Methods Core Facility at BIOCEV, Vestec. 


\section{References}

Agarwal A, Sharma R, Durairajanayagam D, Ayaz A, Cui Z, Willard B, Gopalan B \& Sabanegh E 2015 Major protein alterations in spermatozoa from infertile men with unilateral varicocele. Reproductive Biology and Endocrinology 13 8. (https://doi.org/10.1186/s12958-015-0007-2)

Akhmanova A, Mausset-Bonnefont AL, van Cappellen W, Keijzer N, Hoogenraad CC, Stepanova T, Drabek K, van der Wees J, Mommaas M, Onderwater J et al. 2005 The microtubule plus-end-tracking protein CLIP-170 associates with the spermatid manchette and is essential for spermatogenesis. Genes and Development 19 2501-2515. (https://doi. org/10.1101/gad.344505)

Albrechtova J, Albrecht T, Baird SJ, Macholan M, Rudolfsen G, Munclinger P, Tucker PK \& Pialek J 2012 Sperm-related phenotypes implicated in both maintenance and breakdown of a natural species barrier in the house mouse. Proceedings: Biological Sciences 279 4803-4810. (https://doi.org/10.1098/rspb.2012.1802)

Baccetti BM, Bruni E, Capitani S, Collodel G, Mancini S, Piomboni P \& Moretti E 2006 Studies on varicocele III: ultrastructural sperm evaluation and 18, $\mathrm{X}$ and $\mathrm{Y}$ aneuploidies. Journal of Andrology 27 94-101. (https:// doi.org/10.2164/jandrol.05081)

Baudat F, Buard J, Grey C, Fledel-Alon A, Ober C, Przeworski M, Coop G \& de Massy B 2010 PRDM9 is a major determinant of meiotic recombination hotspots in humans and mice. Science 327 836-840. (https://doi.org/10.1126/science.1183439)

Bianchi PG, Manicardi G, Bizzaro D, Campana A, Bianchi U \& Sakkas D 1996 Use of the guanine-cytosine (GC) specific fluorochrome, chromomycin A3, as an indicator of poor sperm morphology. Journal of Assisted Reproduction and Genetics 13 246-250. (https://doi. org/10.1007/bf02065944)

Cavallini G 2006 Male idiopathic oligoasthenoteratozoospermia. Asian Journal of Andrology 8 143-157. (https://doi.org/10.1111/j.17457262.2006.00123.x)

Chabory E, Damon C, Lenoir A, Kauselmann G, Kern H, Zevnik B, Garrel C, Saez F, Cadet R, Henry-Berger J et al. 2009 Epididymis selenoindependent glutathione peroxidase 5 maintains sperm DNA integrity in mice. Journal of Clinical Investigation 119 2074-2085. (https://doi. org/10.1172/JCl38940)

Cho C, Jung-Ha H, Willis WD, Goulding EH, Stein P, Xu Z, Schultz RM, Hecht NB \& Eddy EM 2003 Protamine 2 deficiency leads to sperm DNA damage and embryo death in mice. Biology of Reproduction 69 211-217. (https://doi.org/10.1095/biolreprod.102.015115)

Davies B, Hatton E, Altemose N, Hussin JG, Pratto F, Zhang G, Hinch AG, Moralli D, Biggs D, Diaz R et al. 2016 Re-engineering the zinc fingers of PRDM9 reverses hybrid sterility in mice. Nature 530 171-176. (https:// doi.org/10.1038/nature16931)

Diagouraga B, Clement JAJ, Duret L, Kadlec J, de Massy B \& Baudat F 2018 PRDM9 methyltransferase activity is essential for meiotic DNA double-strand break formation at its binding sites. Molecular Cell 69 853.e6-865.e6. (https://doi.org/10.1016/j.molcel.2018.01.033)

Dobzhansky T 1936 Studies on hybrid sterility. II. Localization of sterility factors in Drosophila pseudoobscura hybrids. Genetics 21 113-135.

Dowdle JA, Mehta M, Kass EM, Vuong BQ, Inagaki A, Egli D, Jasin M \& Keeney S 2013 Mouse BAZ1A (ACF1) is dispensable for double-strand break repair but is essential for averting improper gene expression during spermatogenesis. PLoS Genetics 9 e1003945. (https://doi.org/10.1371/ journal.pgen.1003945)

El-Kamshoushi AM, Zohdy NI, Abou Khedr NA, Nabhan SA \& Mostafa T 2013 Ultrastructure of the seminiferous tubules in oligoasthenoteratozoospermic men associated with varicocele. Andrologia 45 319-325. (https://doi.org/10.1111/and.12011)

Flachs P, Mihola O, Simecek P, Gregorova S, Schimenti JC, Matsui Y, Baudat F, de Massy B, Pialek J, Forejt J et al. 2012 Interallelic and intergenic incompatibilities of the Prdm9 (Hst1) gene in mouse hybrid sterility. PLoS Genetics 8 e1003044. (https://doi.org/10.1371/journal. pgen.1003044)

Flachs P, Bhattacharyya T, Mihola O, Pialek J, Forejt J \& Trachtulec Z 2014 Prdm9 incompatibility controls oligospermia and delayed fertility but no selfish transmission in mouse intersubspecific hybrids. PLOS ONE 9 e95806. (https://doi.org/10.1371/journal.pone.0095806)

Geraldes A, Basset P, Gibson B, Smith KL, Harr B, Yu HT, Bulatova N, Ziv Y \& Nachman MW 2008 Inferring the history of speciation in house mice from autosomal, X-linked, Y-linked and mitochondrial genes. Molecular Ecology 17 5349-5363. (https://doi.org/10.1111/j.1365294X.2008.04005.x)

Gregorova S \& Forejt J 2000 PWD/Ph and PWK/Ph inbred mouse strains of Mus M. musculus subspecies - a valuable resource of phenotypic variations and genomic polymorphisms. Folia Biologica 46 31-41.

Gregorova S, Gergelits V, Chvatalova I, Bhattacharyya T, Valiskova B, Fotopulosova V, Jansa P, Wiatrowska D \& Forejt J 2018 Modulation of Prdm9-controlled meiotic chromosome asynapsis overrides hybrid sterility in mice. eLife 7 e34282. (https://doi.org/10.7554/eLife.34282)

Howell GR, Munroe RJ \& Schimenti JC 2005 Transgenic rescue of the mouse $t$ complex haplolethal locus Thl1. Mammalian Genome 16 838-846. (https://doi.org/10.1007/s00335-005-0045-8)

Jungwirth A, Giwercman A, Tournaye H, Diemer T, Kopa Z, Dohle G, Krausz C \& European Association of Urology Working Group on Male Infertility 2012 European Association of Urology guidelines on male infertility: the 2012 update. European Urology 62 324-332. (https://doi. org/10.1016/j.eururo.2012.04.048)

Khattri A, Reddy VP, Pandey RK, Sudhakar DV, Gupta NJ, Chakravarty BN, Deenadayal M, Singh L \& Thangaraj K 2012 Novel mutations in calcium/ calmodulin-dependent protein kinase IV (CAMK4) gene in infertile men. International Journal of Andrology 35 810-818. (https://doi.org/10.1111/ j.1365-2605.2012.01302.x)

Kierszenbaum AL 2002 Intramanchette transport (IMT): managing the making of the spermatid head, centrosome, and tail. Molecular Reproduction and Development 63 1-4. (https://doi.org/10.1002/ mrd.10179)

Kierszenbaum AL \& Tres LL 2004 The acrosome-acroplaxome-manchette complex and the shaping of the spermatid head. Archives of Histology and Cytology 67 271-284. (https://doi.org/10.1679/aohc.67.271)

Kierszenbaum AL, Rivkin E \& Tres LL 2011 Cytoskeletal track selection during cargo transport in spermatids is relevant to male fertility. Spermatogenesis 1 221-230. (https://doi.org/10.4161/spmg.1.3.18018)

Kusari F, O'Doherty AM, Hodges NJ \& Wojewodzic MW 2017 Bidirectional effects of vitamin B12 and methotrexate on Daphnia magna fitness and genomic methylation. Scientific Reports 7 11872. (https://doi. org/10.1038/s41598-017-12148-2)

Kusz-Zamelczyk K, Sajek M, Spik A, Glazar R, Jedrzejczak P, LatosBielenska A, Kotecki M, Pawelczyk L \& Jaruzelska J 2013 Mutations of NANOS1, a human homologue of the Drosophila morphogen, are associated with a lack of germ cells in testes or severe oligo-asthenoteratozoospermia. Journal of Medical Genetics 50 187-193. (https://doi. org/10.1136/jmedgenet-2012-101230)

Larson EL, Vanderpool D, Sarver BAJ, Callahan C, Keeble S, Provencio LL, Kessler MD, Stewart V, Nordquist E, Dean MD et al. 2018 The evolution of polymorphic hybrid incompatibilities in house mice. Genetics 209 845-859. (https://doi.org/10.1534/genetics.118.300840)

Liu CH, Tsao HM, Cheng TC, Wu HM, Huang CC, Chen CI, Lin DP \& Lee MS 2004 DNA fragmentation, mitochondrial dysfunction and chromosomal aneuploidy in the spermatozoa of oligoasthenoteratozoospermic males. Journal of Assisted Reproduction and Genetics 21 119-126. (https://doi. org/10.1023/b:jarg.0000029495.22787.83)

Liu S, Yu H, Liu Y, Liu X, Zhang Y, Bu C, Yuan S, Chen Z, Xie G, Li W et al. 2017 Chromodomain protein CDYL acts as a crotonyl-CoA hydratase to regulate histone crotonylation and spermatogenesis. Molecular Cell 67 853.e5-866.e5. (https://doi.org/10.1016/j.molcel.2017.07.011)

Liu M, Ru Y, Gu Y, Tang J, Zhang T, Wu J, Yu F, Yuan Y, Xu C, Wang J et al. 2018 Disruption of Ssp411 causes impaired sperm head formation and male sterility in mice. Biochimica et Biophysica Acta: General Subjects 1862 660-668. (https://doi.org/10.1016/j.bbagen.2017.12.005)

Matzuk MM \& Lamb DJ 2008 The biology of infertility: research advances and clinical challenges. Nature Medicine 14 1197-1213. (https://doi. org/10.1038/nm.f.1895)

Mihola O \& Trachtulec Z 2017 A mutation of the Prdm9 mouse hybrid sterility gene carried by a transgene. Folia Biologica 63 27-30.

Mihola O, Trachtulec Z, Vlcek C, Schimenti JC \& Forejt J 2009 A mouse speciation gene encodes a meiotic histone $\mathrm{H} 3$ methyltransferase. Science 323 373-375. (https://doi.org/10.1126/science.1163601)

Mihola O, Pratto F, Brick K, Linhartova E, Kobets T, Flachs P, Baker CL, Sedlacek R, Paigen K, Petkov PM et al. 2019 Histone methyltransferase PRDM9 is not essential for meiosis in male mice. Genome Research 29 1078-1086. (https://doi.org/10.1101/gr.244426.118) 
Mihola O, Kobets T, Krivankova K, Linhartova E, Gasic S, Schimenti JC \& Trachtulec Z 2020 Copy-number variation introduced by long transgenes compromises mouse male fertility independently of pachytene checkpoints. Chromosoma 129 69-82. (https://doi.org/10.1007/s00412019-00730-8)

Mitchell V, Rives N, Albert M, Peers MC, Selva J, Clavier B, Escudier E \& Escalier D 2006 Outcome of ICSI with ejaculated spermatozoa in a series of men with distinct ultrastructural flagellar abnormalities. Human Reproduction 21 2065-2074. (https://doi.org/10.1093/humrep/del130)

Muller H 1942 Isolating mechanisms, evolution and temperature. Biology Symposium 6 71-125.

Navarro-Costa P, Nogueira P, Carvalho M, Leal F, Cordeiro I, CalhazJorge C, Goncalves J \& Plancha CE 2010 Incorrect DNA methylation of the DAZL promoter CpG island associates with defective human sperm. Human Reproduction 25 2647-2654. (https://doi.org/10.1093/humrep/ deq200)

Nosil P \& Schluter D 2011 The genes underlying the process of speciation. Trends in Ecology and Evolution 26 160-167. (https://doi.org/10.1016/j. tree.2011.01.001)

Oliver PL, Goodstadt L, Bayes JJ, Birtle Z, Roach KC, Phadnis N, Beatson SA, Lunter G, Malik HS \& Ponting CP 2009 Accelerated evolution of the Prdm9 speciation gene across diverse metazoan taxa. PLoS Genetics 5 e1000753. (https://doi.org/10.1371/journal.pgen.1000753)

Parvanov ED, Petkov PM \& Paigen K 2010 Prdm9 controls activation of mammalian recombination hotspots. Science 327 835. (https://doi. org/10.1126/science.1181495)

Parvanov ED, Tian H, Billings T, SaxI RL, Spruce C, Aithal R, Krejci L, Paigen K \& Petkov PM 2017 PRDM9 interactions with other proteins provide a link between recombination hotspots and the chromosomal axis in meiosis. Molecular Biology of the Cell 28 488-499. (https://doi. org/10.1091/mbc.E16-09-0686)

Peng JC \& Karpen GH 2009 Heterochromatic genome stability requires regulators of histone H3 K9 methylation. PLoS Genetics 5 e1000435. (https://doi.org/10.1371/journal.pgen.1000435)

Rahiminia T, Yazd EF, Fesahat F, Moein MR, Mirjalili AM \& Talebi AR 2018 Sperm chromatin and DNA integrity, methyltransferase mRNA levels, and global DNA methylation in oligoasthenoteratozoospermia. Clinical and Experimental Reproductive Medicine 45 17-24. (https://doi. org/10.5653/cerm.2018.45.1.17)

Reichart M, Eltes F, Soffer Y, Zigenreich E, Yogev L \& Bartoov B 2000 Sperm ultramorphology as a pathophysiological indicator of spermatogenesis in males suffering from varicocele. Andrologia 32 139-145. (https://doi. org/10.1046/j.1439-0272.2000.00355.x)

Rieseberg LH 2001 Chromosomal rearrangements and speciation. Trends in Ecology and Evolution 16 351-358. (https://doi.org/10.1016/S01695347(01)02187-5)

Sage RD, Whitney 3rd JB \& Wilson AC 1986 Genetic analysis of a hybrid zone between domesticus and Musculus mice (Mus musculus complex): hemoglobin polymorphisms. Current Topics in Microbiology and Immunology 127 75-85. (https://doi.org/10.1007/978-3-642-71304-0_9)

Santi D, De Vincentis S, Magnani E \& Spaggiari G 2017 Impairment of sperm DNA methylation in male infertility: a meta-analytic study. Andrology 5 695-703. (https://doi.org/10.1111/andr.12379)
Schwahn DJ, Wang RJ, White MA \& Payseur BA 2018 Genetic dissection of hybrid male sterility across stages of spermatogenesis. Genetics $\mathbf{2 1 0}$ 1453-1465. (https://doi.org/10.1534/genetics.118.301658)

Sha YW, Wang X, Su ZY, Wang C, Ji ZY, Mei LB, Zhang L, Deng BB, Huang XJ, Yan $\mathbf{W}$ et al. 2018 TDRD6 is associated with oligoasthenoteratozoospermia by sequencing the patient from a consanguineous family. Gene 659 84-88. (https://doi.org/10.1016/j. gene.2018.03.040)

Singh NP, McCoy MT, Tice RR \& Schneider EL 1988 A simple technique for quantitation of low levels of DNA damage in individual cells. Experimental Cell Research 175 184-191. (https://doi.org/10.1016/00144827(88)90265-0)

Sun F, Fujiwara Y, Reinholdt LG, Hu J, Saxl RL, Baker CL, Petkov PM, Paigen K \& Handel MA 2015 Nuclear localization of PRDM9 and its role in meiotic chromatin modifications and homologous synapsis. Chromosoma 124 397-415. (https://doi.org/10.1007/s00412-015-05113)

Takada Y, Naruse C, Costa Y, Shirakawa T, Tachibana M, Sharif J, Kezuka-Shiotani F, Kakiuchi D, Masumoto H, Shinkai Y et al. 2011 HP1gamma links histone methylation marks to meiotic synapsis in mice. Development 138 4207-4217. (https://doi.org/10.1242/dev.064444)

Torregrosa N, Dominguez-Fandos D, Camejo MI, Shirley CR, Meistrich ML, Ballesca JL \& Oliva R 2006 Protamine 2 precursors, protamine 1/ protamine 2 ratio, DNA integrity and other sperm parameters in infertile patients. Human Reproduction 21 2084-2089. (https://doi.org/10.1093/ humrep/del114)

Turner LM, Schwahn DJ \& Harr B 2012 Reduced male fertility is common but highly variable in form and severity in a natural house mouse hybrid zone. Evolution; International Journal of Organic Evolution 66 443-458. (https://doi.org/10.1111/j.1558-5646.2011.01445.x)

Vicari E, Perdichizzi A, De Palma A, Burrello N, D'Agata R \& Calogero AE 2002 Globozoospermia is associated with chromatin structure abnormalities: case report. Human Reproduction 17 2128-2133. (https://doi.org/10.1093/humrep/17.8.2128)

White MA, Steffy B, Wiltshire T \& Payseur BA 2011 Genetic dissection of a key reproductive barrier between nascent species of house mice. Genetics 189 289-304. (https://doi.org/10.1534/genetics.111.129171)

Yan W 2009 Male infertility caused by spermiogenic defects: lessons from gene knockouts. Molecular and Cellular Endocrinology 306 24-32. (https://doi.org/10.1016/j.mce.2009.03.003)

Zhou J, Du YR, Qin WH, Hu YG, Huang YN, Bao L, Han D, Mansouri A \& Xu GL 2009 RIM-BP3 is a manchette-associated protein essential for spermiogenesis. Development 136 373-382. (https://doi.org/10.1242/ dev.030858)

Received 5 November 2019

First decision 5 December 2019

Revised manuscript received 5 March 2020

Accepted 9 April 2020 